\title{
An approach to assessing the functioning of hierarchical socio-economic systems and decision-making based on the EFRA software package
}

\author{
Roman A. Zhukov \\ E-mail:pluszh@mail.ru
}

Financial University under the Government of the Russian Federation, Tula Branch

Address: 1a, Oruzheynaya Street, Tula 300012, Russia

\begin{abstract}
Modern models and methods for evaluating complex systems are associated with hierarchical socioeconomic systems (HSES) implemented on the basis of software systems (expert systems and decision support systems) and used at the regional and municipal levels of government. As usual, such systems have the functionality of analytics and building scenario variants for the development of research objects. However, they do not give quantified values of the state and impact factors at which the complex system under consideration can come to a given state. At the same time, the question of determining such a set state associated with the construction of standards (expected values) for elements, classes or levels of the HSES is still open. In some cases, to make an informed decision it is sufficient to obtain aggregated quantitative estimates and recommendations concerning the further functioning of the research object. This article presents the author's approach, which allows us to evaluate the functioning of hierarchical socio-economic systems and provides expert opinions for making management decisions implemented on the basis of the EFRA software package. The algorithm includes stages of analysis and synthesis-stages of the basic method of system analysis. The novelty of the proposed approach is the possibility of taking into account the specific conditions of the status and impact of complex systems that provides an opportunity to build their own standard. Additionally, the procedures of standardization and normalization (reduction to a scale from 0 to 1) make it possible to avoid the influence of different units of measurement of results of operation and economies of scale. On the example of regions of the Central Federal district according to data for 2014-2017, estimates of the use of information and telecommunications technologies by the population were obtained, and the optimization problem was solved for the Tula Region, on the basis of which directions related to increasing the region's readiness for digitalization were proposed.
\end{abstract}


Key words: hierarchical socio-economic system; modeling; evaluation; decision-making; software package.

Citation: Zhukov R.A. (2020) An approach to assessing the functioning of hierarchical socio-economic systems and decision-making based on the EFRA software package. Business Informatics, vol. 14, no 3, pp. 82-95. DOI: 10.17323/2587-814X.2020.3.82.95

\section{Introduction}

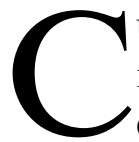
urrently, management activities are increasingly using software tools that ensure informed decision-making, including at the regional and municipal levels. At the same time, most systems (expert systems and decision support systems, DSS) based on built-in models, in addition to Analytics, allow you to form scenario variants of the development of the research object, but do not offer quantitative recommendations aimed at optimizing the functioning of the research object, including the hierarchical socio-economic system (SES), in accordance with the goal and tasks to be solved.

Currently, there are more than a hundred software platforms for modeling socio-economic processes, as well as separate software complexes developed for a specific purpose, including for regional-level HSES.

Thus, from 1975 to 1990, under the leadership of V.I. Gurman, the "Region" set of models was developed [1]. They are based on mathematical models that describe the region at three levels of hierarchy and consider it as an open system, in the form of a set of social, natural and economic subsystems. The dseemodel 1.0 (Dynamic Socio-Ecological-Economic model) software package is well known as a regional modeling tool [2].

Over the past twenty years, CEMI RAS has been conducting research related to modeling complex systems of macro- $[3,4]$, meso- $[5,6]$ and micro-levels [7] based on computer mod- eling systems, including econometric models and neural networks, computable General equilibrium models (CGE models), dynamic stochastic General equilibrium models (DSGE models) and agent-oriented models. Among the CGE models, we note the following: the model of the Russian economy "RUSEC," "Russia: Center-Federal districts," "RUSEC natural monopolies," "RUSEC - Gazprom," and "Social Russia," a model of the socioeconomic system of Russia with built-in neural networks. Agent models are represented by such products as the Russian agent model, the regional Governor model, the Eurasia model, and the Roscosmos model, among others. ${ }^{1}$

Software complexes based on agent-oriented models of "smart cities" are being developed on the basis of the situation centers of the Russian regions [8].

At the micro-level (enterprise level), information systems (IS) are successfully used to solve optimization problems: in production companies, logistics and design organizations (including DSS on SAP, Oracle and IBM platforms), as well as intelligent information systems (AIS), the classification of which is presented in [9]. A number of IP systems are used at the Federal and regional levels. For example, the Ministry of Economic Development of the Russian Federation and its subordinate organizations have about 25 external and 11 internal systems that support management decisions ${ }^{2}$. Most of them are related to document management, providing legal reference informa-

\footnotetext{
${ }^{1}$ Laboratory of agent-based modeling (http://abm.center/publications/)

${ }^{2}$ http://www. http://economy.gov.ru
} 
tion and providing public services. A number are used for analytical research and forecasts, for example: "Monitoring, analysis and forecasting of socio-economic development and the financial condition of the regions of the Russian Federation," "PROGNOSis," "Passport of the region," "Catharsis" [10]. The first of the presented ICS allows you to make forecasts and conduct simulation with the possibility of selecting the functional form of models by the user. Unfortunately, the platform does not provide the ability to generate generalized indicators, and also does not allow you to balance the values of individual indicators based on these indicators (bring them to a given value) by searching for optimal significant factors.

At the level of a region (subject of the Russian Federation) or a municipality, it is often necessary to make enlarged (to a certain extent) assessments of the functioning of the management object and recommendations for its development and decision-making. Detailed solutions are provided during the development of appropriate measures. Thus, approaches and tools that do not require users to have special skills in the field of modeling socio-economic processes and in-depth knowledge in the field of econometric modeling and statistical processing of information, and that could provide reasonable quantitative recommendations to government bodies at various levels (region, municipality, company), aimed at optimal, in terms of resources used and costs for implementing the relevant activities, become particularly relevant with development of the management object.

The aim of this article is to present and implement an approach to assessing the functioning of the HSES using a modified software package $[11,12]$, using the example of studying the use of information and communication technologies (ICT) by the population of the regions of the Central Federal District, including the Tula Region.

\section{Formalized description of the approach}

The proposed approach is based on the classical method of system analysis, which includes the stages of analysis and synthesis of management decisions [13-15].

We will consider HSES as open territorial socio-economic systems of the regional level (meso-level) with a mixed type of economic relations, in the context of the institutional type of social relations, with an emphasis on their subsystems of the environmental type, interacting with subsystems of object, process and project types within the space-time classification based on the system paradigm [16].

By functioning, we mean the activity associated with the performance of certain works by the object of research in relatively unchanged conditions, with some restrictions, aimed at achieving its goals, including ensuring the life of both its own and other related objects of interest to it. By the assessment of the functioning of the HSES, we mean the quantitatively expressed results of its life activity (its individual components), - value (axiological) and practical (epistemological and axiological) significance from the point of view of the acting and cognizing object, - allowing us to analyze the correlation of such results with normative (expected, planned) values, taking into account specific conditions (factors of state and impact).

This study examines one of the levels $L_{p}$ of the hierarchical socio-economic system, which is a partially ordered set of $\langle H, R\rangle$ elements $k_{p,(p-1), v_{p}, s_{q}}$, between the elements of which a relation of non-strict order $R$ is defined [1719]. Here $p$ is the hierarchy level (subset $L_{p}$ ); $(p-1)$ is number of the level element $p-$ 1 , that the $(p-1)$-level element is subordinate to $p$-level element; $v_{p}$ is element number; $s_{q}$ is element class number (a class is a subset of elements grouped by one of the pos- 
sible bases). Examples of classifications can be a set of elements that carry out activities in accordance with the OKVED (all-Russian classifier of economic activities), sector classification [20], space-time classification [21], the division of the HSES into social, economic and environmental components (subsystems - classes) [22]. Each of the elements is characterized by four types of features (it is allowed to study elements through their feature descriptions). These include:

$\downarrow$ performance indicator $y_{p,(p-1), v_{p}, s_{q}}(t)$ is the actual value of the result of the element's operation. For example, for a region, this is the volume of gross domestic product (GDP) by regions for the corresponding type of OKVED activity

$\downarrow$ state factors $x_{p,(p-1), v_{p}, s_{q}, j}(t)$ (for example, average annual number of persons employed by types of economic activity);

impact factors $z_{p,(p-1), v_{p}, s_{q}, u}(t)$ (for example, investments in fixed capital by kinds of economic activity);

$\checkmark$ normative (expected) performance indicator $\hat{y}_{p,(p-1), v_{p}, s_{q}}(t)$ is the norm.

Here $t$ is the time period, $t=1, \ldots, T, T$ is the number of periods; $j=1, \ldots, J ; J ; \mathrm{J}$ is the number of state factors; $u=1, \ldots, u$; $U$ is the number of impact factors. In this case, there is a function such that:

$$
\begin{gathered}
f_{p,(p-1), s_{q}}: x_{p,(p-1), v_{p}, s_{q}, j}(t), \\
z_{p,(p-1), v_{p}, s_{q}, u}(t) \rightarrow \hat{y}_{p,(p-1), v_{p}, s_{q}}(t) .
\end{gathered}
$$

Then the values of the partial (for a single $v_{p}$-th element) and integral (for a set of elements with an index $v_{p}$ which is belonging to the same class) performance indicators will be determined by the formulas [23]:

$$
\xi_{p,(p-1), s_{q}}(t)=\frac{y_{p,(p-1), v_{p}, s_{q}}^{0}(t)}{\hat{y}_{p,(p-1), v_{p}, s_{q}}^{0}(t)},
$$

$\xi_{p, v_{p}, s_{q}}(t)=\frac{\sqrt{\sum_{i_{1}=1}^{I} \sum_{i_{2}=1}^{I} r_{p, i_{1}, i_{2}, s_{q}} \cdot y_{p, i_{1}, v_{p}, s_{q}}^{0}(t) \cdot y_{p, i_{2}, v_{p}, s_{q}}^{0}(t)}}{\sqrt{\sum_{i_{1}=1}^{I} \sum_{i_{2}=1}^{I} \hat{r}_{p, i_{1}, i_{2}, s_{q}} \cdot \hat{y}_{p, i_{1}, v_{p}, s_{q}}^{0}(t) \cdot \hat{y}_{p, i_{2}, v_{p}, s_{q}}^{0}(t)}}$

where $r_{p, i_{1}, i_{2}, s_{q}}, \hat{r}_{p, i_{1}, i_{2}, s_{q}}$ are corresponding paired correlation coefficients between $i_{1}$-th $y_{p, i_{1}, v_{p}, s_{q}}^{0}$, $\hat{y}_{p, i_{1}, v_{p}, s_{q}}^{0}$ and $i_{2}$-th $y_{p, i_{2}, v_{p}, s_{q}}^{0}(t), \hat{y}_{p, i_{1}, v_{p}, s_{q}}^{0}$ variables (performance indicators are actual and expected (normative), respectively, the values of the latter are determined using the production function $(\mathrm{PF}))\left(i_{1}, i_{2}=1, \ldots, I\right.$ is the number of performance indicators); the index " 0 " shows that the normalization procedure was performed (bringing it to a scale from 0 to 1 ) after switching from absolute values of features to their standardized forms. The functional form and parameters of the PF can be obtained using factor analysis of dependencies [24]. The expression in the denominator (3) will be called the aggregated PF (APF).

If the value of the indicator for the $v_{p}$-th element (subsystem) is greater than one, then the functioning of the object under consideration is satisfactory.

The proposed indicator has a number of useful properties that distinguish it from other generalized evaluation indicators that differ in the way of aggregation (convolution) of particular indicators, such as the average of various types [25], summation using weight coefficients [26], or the formation of latent variables [27]. These properties include:

$\checkmark$ dimensionality, which allows you to compare features that are of different nature and relate to different processes (for example, economic and social);

$\downarrow$ normalization, which provides a reduction in the impact of economies of scale and visibility of results (bringing to a scale from 0 to 1 );

- normability, which makes it possible to compare the estimates obtained with the standard (expected value). 
The presented integral (generalized) performance indicator takes into account the relationship of particular indicators that characterize the functioning of the subsystem and its elements included in the class, as well as the specific conditions under which the research object operates.

The following indicator is used to assess the balanced functioning of the HSES (the coefficient of harmony):

$$
H_{A p}=1-\frac{\sigma\left(\xi_{p, i}\right)}{M\left(\xi_{p, i}\right)}, H_{A p, s_{q}}=1-\frac{\sigma\left(\xi_{p, i, s_{q}}\right)}{M\left(\xi_{p, i, s_{q}}\right)},
$$

where $\sigma\left(\xi_{p, i}\right), \sigma\left(\xi_{p, i, s_{q}}\right)$ are means;

$$
\sigma\left(\xi_{p, i}\right), \sigma\left(\xi_{p, i, s_{q}}\right) \text { are standard deviations, }
$$

$i=1, \ldots, I, I$ is the number of partial performance indicators that characterize the class $s_{q}$ (in the case of constructing the level's harmony coefficient $i=1, \ldots, Q, Q$ is the number of integral performance indicators corresponding to the number of classes);

$\xi_{p, i}, \xi_{p, i, s_{q}}$ are variables whose values are determined according to (2) and (3).

Being a derivative of partial and integral performance indicators, the harmony coefficient retains a number of their properties; its value does not exceed one and characterizes the degree of compliance of all indicators with the normative (expected) values under specific conditions of the object of research, as well as their compliance with each other. This distinguishes the coefficient of harmony from other indicators based, for example, on the assessment of the share (contribution) of each of the subsystems to the overall result of the system [28], the intensity of interaction [16] or the coupling coordinated [29].

A set of ten indicators is used to assess the effectiveness of the HSES, including indicators of the functioning effectiveness (four indicators), impact effectiveness (four indicators), and management effectiveness (two indicators). The General formula is defined as follows [23]:

$$
E f(t)=\frac{\xi(t) / \xi\left(t_{0}\right)}{x(t) / x\left(t_{0}\right)},
$$

where $\xi(t), \xi\left(t_{0}\right), x(t), x\left(t_{0}\right)$ are partial (or integral) indicators of the performance of the element (subsystem) and its factor attribute (state factors or impact factors, or a generalized factor determined similarly to the numerator (3)) of the current and basic or previous period correspondently. Depending on the type of indicators and factors that are respectively in the numerator and denominator of the expression (5), ten types of performance indicators are formed.

Values of indicators (5) that are greater than 1 can be interpreted as follows: the change in the result is greater than the "cost" of changing it.

The performance indicators presented, in addition to the traditional ones that characterize the ratio of results and costs for their implementation (for example, profitability, etc.) or technical efficiency indicators [30], are not "distorted" by the measurement units used and retain the property of normability.

After the analysis stage of the HSES, which identifies the results of its functioning (its subsystems or elements) that do not meet the expected (normative) values, the decision synthesis stage is performed. For elements (subsystems) for which the partial (integral) performance indicators are less than one, it is necessary to implement the optimization procedure, that is, to find such factors of state and impact (or their changes), in which the expected (normative) result of the functioning of the considered elements (subsystems) would correspond to the actual results. The optimization procedure should be performed using standardized models [31]. One of the particular problems can be formulated as follows.

Let the normative (expected) result $\hat{y}_{p,(p-1), v_{p}, s_{q}}^{0}(t)$ for a population element $k_{p,(p-1), v_{p}, s_{q}}$ be presented in a general case as: 


$$
\begin{gathered}
\hat{y}_{p,(p-1), v_{p}, s_{q}}^{0}(t)=f\left(x_{p,(p-1), v_{p}, s_{q}, j}^{*}(t)+\right. \\
+\Delta x_{p,(p-1), v_{p}, s_{q}, j}^{*}(t), \\
\left.z_{p,(p-1), v_{p}, s_{q}, s}^{*}(t)+\Delta z_{p,(p-1), v_{p}, s_{q}, s}^{*}(t)\right)^{0},
\end{gathered}
$$

where $j, s$ are indexes of state factors $x_{p,(p-1), v_{p}, s_{q}, j}^{*}(t)$ and indexes of impact factors $z_{p,(p-1), v_{p}, s_{q}, s}^{*}(t)$;

$\Delta x_{p,(p-1), v_{p}, s_{q}, j}^{*}(t), \quad$ and $\Delta z_{p,(p-1), v_{p}, s_{q}, s}^{*}(t)$ are respective possible increments (standardized (index $\left.\ll^{*} »\right)$ ) for them;

$t$ is time (period);

The normalization procedure is indicated by the upper index " 0 ". The functional form of $f$ can be arbitrary (linear or nonlinear).

The problem is posed: at what possible values $x_{p,(p-1), v_{p}, s_{q}, j}^{*}(t)+\Delta x_{p,(p-1), v_{p}, s_{q}, j}^{*}(t), z_{p,(p-1), v_{p}, s_{q}, s}^{*}(t)+$ $\Delta z_{p,(p-1), v_{p}, s_{q}, s}^{*}(t)$ (for known $x_{p,(p-1), v_{p}, s_{q}, j}^{*}(t)$ and $\left.z_{p,(p-1), v_{p}, s_{q}, s}^{*}(t)\right)$ for known and ) an expression similar to the (2) would tend to unity:

$$
\frac{y_{p,(p-1), v_{p}, s_{q}}^{0}(t)}{\hat{y}_{p,(p-1), v_{p}, s_{q}}^{0}(t)} \rightarrow 1,
$$

where $y_{p,(p-1), v_{p}, s_{q}}^{0}(t)$ are values of a normalized PF with known functional form, parameters, factors $x_{p,(p-1), v_{p}, s_{q}, j}^{*}(t), z_{p,(p-1), v_{p}, s_{q}, s}^{*}(t)$ and unknown factors $\Delta x_{p,(p-1), v_{p}, s_{q}, j}^{*}(t)$ and $\Delta z_{p,(p-1), v_{p}, s_{q}, s}^{*}(t)$;

$y_{p,(p-1), v_{p}, s_{q}}^{0}(t)$ are normalized actual values of the result of the element functioning $k_{p,(p-1), v_{p}, s_{q}}$ over a period of time $t$.

Based on this requirement, the target function can be represented as the difference between the actual and calculated values of the results of the operation of the research object with unknown $\Delta x_{p,(p-1), v_{p}, s_{q}, j}^{*}(t)$, and $\Delta z_{p,(p-1), v_{p}, s_{q}, s}^{*}(t)$, which are in the numerator and denominator of the equation (7):

$$
F(t)=\hat{y}_{p,(p-1), v_{p}, s_{q}}^{0}(t)-y_{p,(p-1), v_{p}, s_{q}}^{0}(t) \rightarrow \min .
$$

Let there be restrictions, in general, of the non-linear form

$$
\begin{gathered}
g_{l}\left(x_{p,(p-1), v_{p}, s_{q}, j}^{*}(t)+\Delta x_{p,(p-1), v_{p}, s_{q}, j}^{*}(t),\right. \\
\left.z_{p,(p-1), v_{p}, s_{q}, q_{1}}^{*}(t)+\Delta z_{p,(p-1), v_{p}, s_{q}, q_{1}}^{*}(t)\right)^{0}, \\
\left.z_{p,(p-1), v_{p}, s_{q}, q_{2}}^{*}(t)+\Delta z_{p,(p-1), v_{p}, s_{q}, q_{2}}^{*}(t)\right)=0,
\end{gathered}
$$

where $l$ is the number of constraints;

$j$ is the index factors in the state

$q_{1}, q_{2}$ are indexes of unmanaged and managed impact factors s respectively;

$$
\begin{gathered}
\left\{z_{p,(p-1), v_{p}, s_{q}, s}^{*}(t)\right\}= \\
=\left\{z_{p,(p-1), v_{p}, s_{q}, q_{1}}^{*}(t)\right\} \cup\left\{z_{p,(p-1), v_{p}, s_{q}, q_{2}}^{*}(t)\right\}
\end{gathered}
$$

is the impact factors set.

We need to find a solution in which function (8), if there are constraints (9), would take the minimum value.

If the found values $x_{p,(p-1), v_{p}, s_{q}, j}^{*}(t)+$ $\Delta x_{p,(p-1), v_{p}, s_{q}, j}^{*}(t) \quad$ and $\quad z_{p,(p-1), v_{p}, s_{q}, s}^{*}(t) \quad+$ $\Delta z_{p,(p-1), v_{p}, s_{q}, s}^{*}(t)$ are substituted in (2), the value of the performance indicator will be equal to one, which will indicate that under these conditions, the result of the element's $k_{p,(p-1), v_{p}, s_{q}}$ functioning can be considered satisfactory.

If the optimality criteria for the functioning of HSES or its subsystems will be the equality unit of the integral index, the coefficient of harmony, performance indicators or their combinations, the search for relevant factors of the status and impact of HSES can be reduced to a multi-objective optimization problem, whose solution can be accomplished by several methods [31-34]. The values obtained $\Delta x_{p,(p-1), v_{p}, s_{q}, j}^{*}(t)$ and $\Delta z_{p,(p-1), v_{p}, s_{q}, s}^{*}(t)$ can be recommendations for various levels of government when making informed management decisions and developing appropriate measures.

Thus, the approach for HSES presented within the framework of the accepted classification and hierarchy allows us to implement the basic methodology of system analysis, which includes the stages of analysis of complex systems and synthesis of management decisions. 


\section{Conceptual scheme and algorithm for implementing the approach}

The conceptual scheme for implementing the approach consists of four generalized blocks (Figure 1) that implement the corresponding algorithm.

The first block provides for loading data. An example is statistical data for the regions of the Central Federal District (CFD), grouped by year.

The second block provides for the implementation of the following functions.

1. Correlation analysis. For the significance level set by the user, the values of the Pearson correlation coefficients, $t$-statistics, and its critical value between feature descriptions of elements for the specified periods are output. Significant coefficients are highlighted in color.

2. Factor analysis of dependencies.

2.1. Selection of effective and factor features (state factors and impact factors) for building models. There is a choice of several effective features.

2.2. Choosing the functional form of models. Provides a choice of linear, logarithmic, exponential, and power multiplicative forms.

2.3. The choice of evaluation period. Provides a choice of the start and end periods. If only the number of periods is specified, the estimate is made starting from the last specified period.

2.4. The construction of models. This function is implemented using two methods: the ordinary least squares method (OLS) (with opportunity of backward selection). This generates models for absolute and standardized variables (standardized models).

2.5. Evaluating the quality of models and their parameters. It includes an assessment of the quality of models using the Fisher criterion (the coefficient of determination is evaluated) and model parameters using the Student criterion, with the corresponding calculation of calculated and critical values and standard errors, as well as the subsequent formation of an expert opinion based on the results of factor analysis of dependencies. The quality of models can be evaluated for both linearized and non-linearized models.

2.6. Additional testing for multicollinearity of factors (Farrar-Glauber test) and for heteroscedasticity of a number of residues (Spearman rank correlation test).

2.7. Calculation of additional characteristics: the average relative error of actual and normative values, as well as elasticity coefficients for the corresponding factors.

2.8. Point and interval estimation of expected (normative) values of performance indicators. The following formula is used:

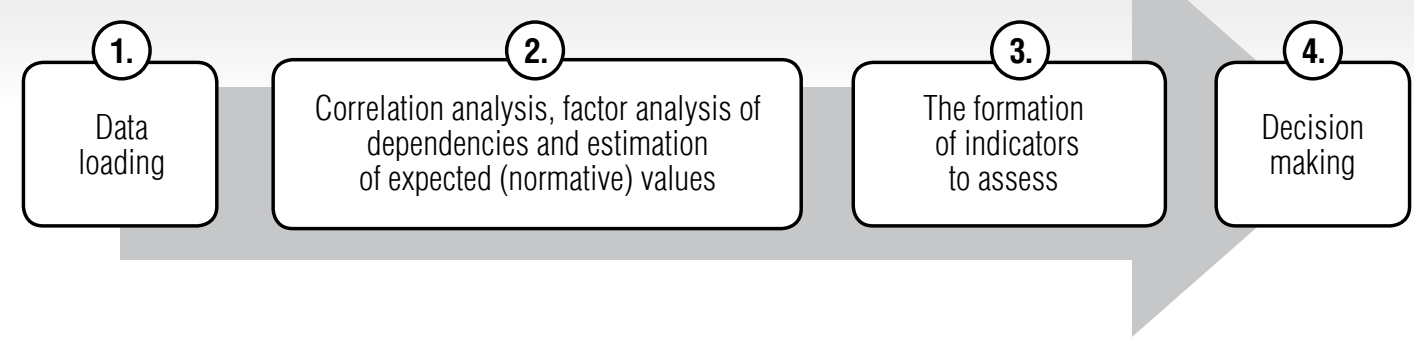

Fig. 1. Conceptual generalized scheme of the algorithm 


$$
\begin{gathered}
\hat{y}_{p,(p-1), v_{p}, s_{q}}=\hat{y}_{p,(p-1), v_{p}, s_{q}} \pm t_{1 \alpha, n-J-1} \cdot s_{y} \cdot \\
\cdot\left(1+[X Z]_{0}^{T} \cdot\left([X Z]^{T} \cdot[X Z]\right)^{-1} \cdot[X Z]_{0}\right)^{1 / 2},
\end{gathered}
$$

where $s_{y}$ is standard error;

$\hat{y}_{p,(p-1), v_{p}, s_{q}}$ are calculated values using a formula similar to (6), but for absolute values of factor and result attributes;

$t_{1 \alpha, n-J-1}$ is confidence level (determined from the Student distribution table), $\alpha$ is significant level, $n$ is the number of observations, $J$ is the number of model parameters;

$[X Z]$ is matrix of state and impact factors;

$[X Z]_{0}$ is vector of expected values (this vector can be entered in the appropriate form, or downloaded from a file).

2.9. Passing the built models to the block for generating evaluation indicators. The transfer can be performed in two ways: complete (in the case of simultaneous evaluation of several selected performance indicators) or backward selection (in the case of building and evaluating models based on a single performance indicator). If the resulting indicator has a negative character, then the procedure for inverting the indicator is provided (replacing its values with reverse values with a "minus" sign).

3. The block for generating evaluation indicators is launched after entering the initial data and working out the second block. It provides for the implementation of the following operations.

3.1. Setting the evaluation periods "from and to" and entering the number of elements belonging to only one element of a higher level. In addition, operation 3.1. is used to check whether input data is correct. If the entered number and the evaluation period do not match, a message is displayed indicating the reason why subsequent procedures cannot be started.

3.2. Selection of effective and factor features for the formation of private indicators for evaluating the functioning of the selected elements and their totality, forming a class or a set of classes.
3.3. Calculation of partial (formula (2)) and integral (formula (3)) indicators of performance, harmony (formula (4)) and efficiency of various types (formula (5)).

3.4. Setting the required output results for evaluating the functioning of elements and classes (classes) of the same level of the HSES.

4. The unit of decision-making. Starts after the third block is completed. It includes the following procedures.

4.1. Selection of performance indicators for optimization.

4.2. Setting the required optimization parameters, including an additional optimization option for an integral (generalized) indicator, as well as optimization for each of the factor features.

4.3. Optimization. At this stage, an optimization algorithm is implemented, which consists in searching for state and impact factors separately and by a generalized factor for particular integral performance indicators. In the present version, the restriction (9) is not used.

Each of the blocks provides output of results in the form of tables and graphs, as well as expert opinions.

Thus, the conceptual scheme and the algorithm presented allow us to implement the proposed approach to evaluating the functioning of levels, classes and individual elements of the HSES.

\section{Results of the assessment of the use of information and communications technologies by the population of the Central Federal District and the Tula Region}

The approach presented here was tested on the example of the regions of the Central Federal District (excluding Moscow).

The choice of evaluation indicators was based on available information obtained from open sources and traditionally used in the analysis of the level of information and communi- 
cations technologies (ICT) development at the regional level, as well as significant factors that could influence such results.

Due to limited information and the lack of information for a number of indicators up to 2014 (although the methodology allows using data with different lengths (number of points)), the assessment period 2014-2017 was selected for the Central Federal District regions. The information base was compiled according to Rosstat data. As a tool, the EFRA software package was used, which implements the presented approach [35].

Based on the correlation analysis (the corresponding module of the EFRA program was applied with $t$-statistics for the significance level $\alpha=0.05$ ), 7 out of 10 effective features and 6 out of 12 factor features (func- tioning factors) were selected that characterize the peculiarities of ICT use in the regions. These features were used in the construction of partial and integral performance indicators (indicators) (Table 1). All cost indicators were adjusted for the level of inflation and brought to the level of 2007.

The regression analysis module is used for building models. Since the choice of the functional form of models is not justified in the research (this requires more in-depth study) due to the lack of information about them, the linear form of models is accepted as the simplest in terms of evaluating its parameters. We used the least square method (backward selection) to build the models and insignificant factors were excluded for $\mathrm{t}$-statistics with the level of significance $\alpha=0.05$.

Results and factors (conditions)

\section{of functioning of the Central Federal District regions}

Table 1.

\begin{tabular}{c|l|c}
\multicolumn{1}{|c}{ No } & \multicolumn{1}{|c}{ State and impact factors } & Designation \\
\hline 1 & Average annual number of persons employed, thousand pers. & $x_{1}$ \\
\hline 2 & Nominal average monthly wages of employees of organizations, rubles & $x_{2}$ \\
\hline 3 & Percentage of households with a personal computer, \% & $x_{3}$ \\
\hline 4 & Consolidated budget expenditures by education, million rubles & $z_{1}$ \\
\hline 5 & Consolidated budget expenditures by social policy, million rubles & $z_{2}$ \\
\hline 6 & The costs of ICT (total), million rubles & $z_{3}$ \\
\hline \multicolumn{2}{|c|}{ Results } & $y_{1}$ \\
\hline 7 & Percentage of households with Internet access, \% & $y_{2}$ \\
\hline 8 & Percentage of households with broadband Internet access, \% & $y_{3}$ \\
\hline 9 & Users of the Internet, \% & $y_{4}$ \\
\hline 10 & Users who access the Internet every day, \% & $y_{5}$ \\
\hline 11 & Number of connected mobile subscriber devices per 1000 population, units & $y_{6}$ \\
\hline 12 & The number of active subscribers of broadband access to the Internet, individuals, thousand pers. \\
\hline 13 & Number of active mobile subscribers using Internet access services, thousand pers. & $y_{7}$ \\
\hline
\end{tabular}


Factors related to consolidated budget expenditures were not included in the models, since the coefficients describing their impact on the performance indicator were statistically insignificant. From a qualitative point of view, this may be due to the lack of information about the targeted use of expenditures in terms of training the population in computer literacy and social support, for example, for the purchase of office equipment. Therefore, when developing proposals, we should not exclude from consideration the organization of educational events and social support measures aimed at increasing the level of use of ICT in the life of the population.

The results $\hat{y}_{6}^{*}$ and $\hat{y}_{7}^{*}$ are more related to the average annual number of persons employed than to the level of wages. At the same time, $\hat{y}_{5}^{*}$ depends on the nominal average monthly wages of employees of organizations. The results $\hat{y}_{5}^{*}$, $\hat{y}_{6}^{*}$ and $\hat{y}_{7}^{*}$ also significantly depend on the ICT costs that occur in the region.

The models presented can be used both for developing forecasts and calculating expected values of regional performance results, and for evaluating them, as well as for making management decisions.

Using the equations (1)-(3), performance indicators were calculated $(i=1, \ldots, 7$ corresponds to the number of the performance indicator in Table 1) for the regions of the Central Federal District, for which it is possible to assess the level of the population in terms of ICT use. The results are shown in Figure 2 in 2017.

The results show that, although in absolute values the Tula Region ranks second among all the regions of the Central Federal District in most indicators, when taking into account the existing conditions (factors) identified as significant, the functioning of the Tula Region in a number of indicators does not reach the standard (expected) value. This indicates insufficient use of the region's opportunities (potential) to increase the level of digitalization.
For the Tula Region, using the decisionmaking module of the EFRA complex, in the simplest case (the task of optimizing each indicator separately without taking into account restrictions), the state and impact factors were found, at which the values of indicators would reach the standard.

The solution of such a problem can be interpreted qualitatively as follows.

Interpretation 1: what are the values $\Delta x_{k, i, j}^{*}(t)$, $\Delta z_{k, i, q}^{*}(t)$ of overspending (underutilization) of state and impact factors in the $k$-th region.

Interpretation 2: what values $\Delta x_{k, i, j}^{*}(t)$, $\Delta z_{k, i_{2} q}^{*}(t)$ should be used to intensify the use of $x_{k, i, j}^{*}(t)$ and rationalize $\Delta z_{k, i, q}^{*}(t)$ in order to achieve the norm in the $k$-th region.

The calculation results for the Tula Region are shown in Table 2. This table indicates:

$\diamond \xi_{i}$ corresponds to the assessment of the i-th result of functioning $y_{i}$;

$\downarrow$ the sign indicates by how many percent there is an overspend ("-") or excess ("+") of the factor attribute, so the norm is not reached;

$\diamond 0$ indicates that optimization is not required for this subject;

$\downarrow>100$ indicates that the norm cannot be reached if only one factor changes,

$\checkmark$ the dash indicates that this factor is not used in the model.

The results obtained can serve as a basis for a more in-depth analysis of the causes of underutilization (overspending) of existing conditions (factors) and further management decision-making, as well as the development of appropriate measures.

It can be concluded that the areas to focus on when developing measures to increase the level of ICT use by the population of the Tula Region include:

the organization of educational services, including with the support of state and local governments; 
a)

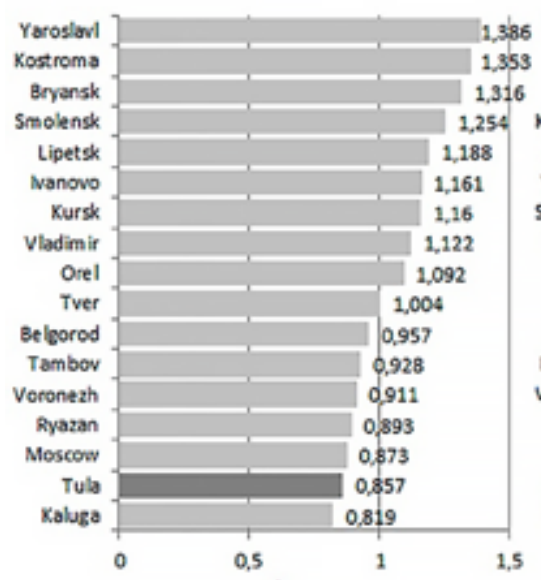

d)

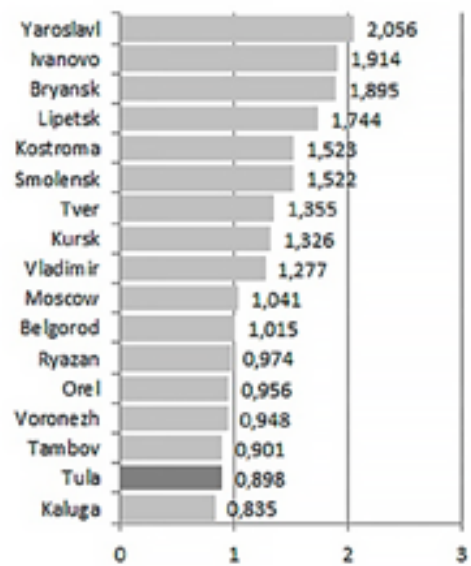

b)

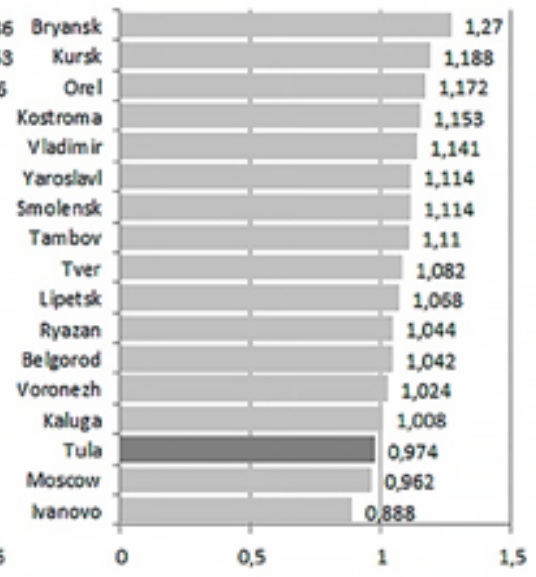

e)

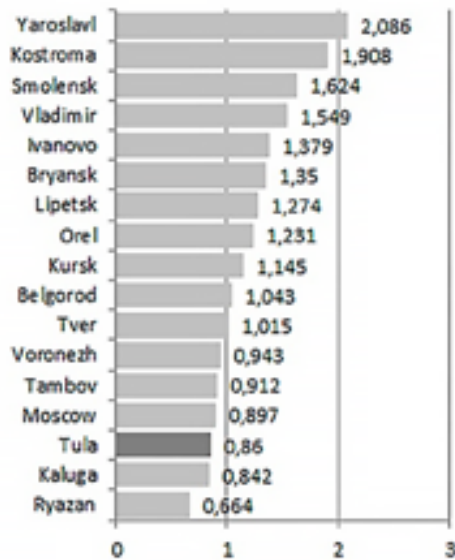

g)

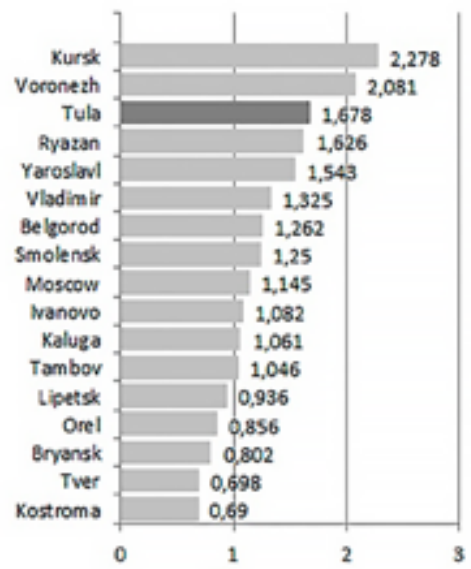

c)

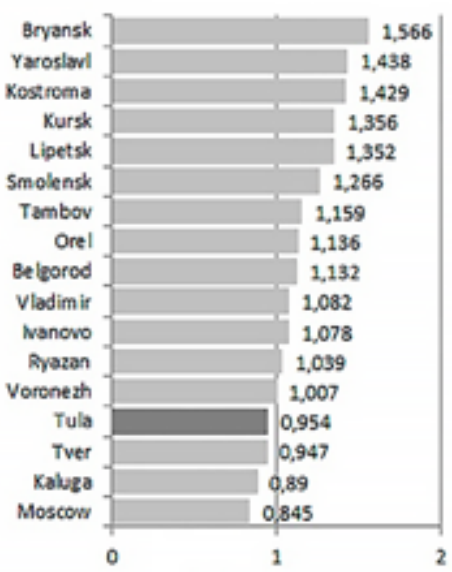

f)

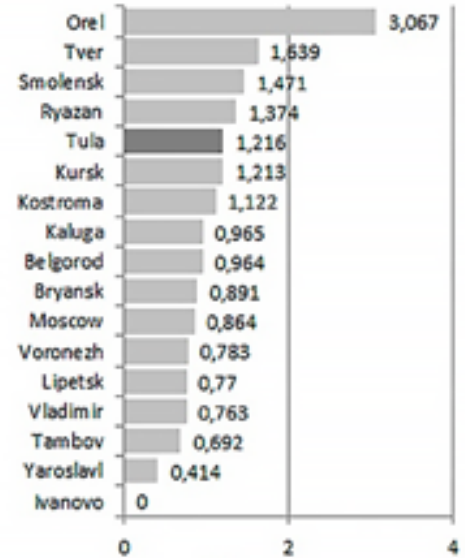

h)

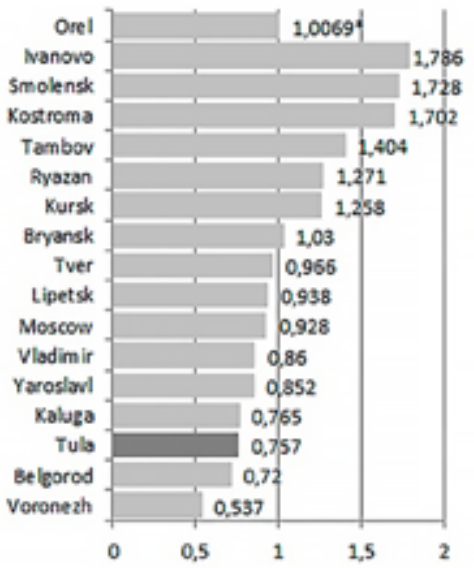

Fig. 2. Values of performance indicators for the Central Federal District regions in 2017:

a) the integral (generalized) indicator $\xi_{\text {; }}$

b) $\xi_{1} ; \quad$ c) $\xi_{2} ; \quad$ d) $\xi_{3} ;$ e) $\xi_{4} ;$ f) $\xi_{5} ; \quad$ g) $\xi_{6} ; \quad$ h) $\xi_{6}$ 
Optimization of performance indicators based on 2017 data for the Tula Region by respective factors, $\%$

Table 2.

\begin{tabular}{c|c|c|c|c|c|c|c|c} 
No & $\begin{array}{c}\text { Factor } \\
\text { Indicator }\end{array}$ & $\xi_{1}$ & $\xi_{2}$ & $\xi_{3}$ & $\xi_{4}$ & $\xi_{5}$ & $\xi_{6}$ & $\xi_{7}$ \\
\hline 1 & $x_{1}$ & - & - & - & - & - & 0 & -16.99 \\
\hline 2 & $x_{2}$ & - & - & - & - & 0 & - & - \\
\hline 3 & $x_{3}$ & -0.84 & -1.81 & -4.34 & -6.73 & - & - & - \\
\hline 4 & $x_{4}$ & - & - & - & - & 0 & 0 & $>100$ \\
\hline
\end{tabular}

\footnotetext{
$\downarrow$ the welfare of the population for the use of ICT;
}

$\downarrow$ the increasing employment in where ICT is used;

$\downarrow$ the change in salary level;

$\checkmark$ changes in both the volume of ICT expenditures and the structure of the use of allocated funds, which requires a more in-depth study (it is not provided for in this study).

In terms of further work in the field of increasing the level of ICT use by the population using the approach presented, the following steps can be proposed:

1. In-depth assessment of conditions (state factors and impact factors) on the level of digital literacy of the population by expanding the information base of the study, both in terms of sectional and cross-sectional data in the context of municipalities and regions, with the construction of regional development models with point and interval estimates in the short and medium term;

2. The assessment of the effectiveness of digitalization management in the region;

3. The assessment of the harmony (balance) of the region's functioning in terms of digitalization using the author's methodology;

4. The detailed elaboration of measures, including in quantitative terms on the basis of several classes of optimization problems to be solved, aimed at ensuring balanced growth and increasing digital literacy of the region's population.

\section{Conclusion}

This article presents an approach to assessing the functioning of complex systems (HSES) and decision-making, implemented in the EFRA software package. The difference between the approach used and similar ones is the ability to take into account the specific conditions for the functioning of the HSES and the formation of their own standards for them. Designed indicators allow you to compare different objects that operate in different conditions, and the procedures used to build such indicators eliminate the influence of units of measurement and economies of scale. The integral indicator takes into account the mutual influence of particular results of the HSES functioning, which is rarely used in the formation of integral estimates. The harmony coefficient and performance indicators in combination with partial and integral performance indicators form a system of indicators for evaluating the functioning of the HSES, and the optimization method used allows you to find the values of state factors and impacts to achieve the normative values of the estimated indicators of the object of research. 
Based on the example of the Central Federal District regions, the level of ICT use by the population of the subjects of the Russian Federation was analyzed for 2014-2017, and the necessary changes in the state and impact factors were found for the Tula Region, in which the evaluation indicators considered would reach the normative (expected) value. On the basis of the results obtained using the EFRA software package, a number of guidelines for the development of the region in terms of ICT and improved digital literacy of the population of the Tula Region aimed, ultimately, at increasing the readiness of the region for digitization.

\section{References}

1. Stolbov A.B. (2017) Software for complex studies of social-ecological and economic systems based on the "Region" models: an analytical review. Program systems: Theory and Applications, vol. 8, no 4 (35), pp. 47-83 (in Russian). DOI: 10.25209/2079-3316-2017-8-4-47-83.

2. Gurman V.I., Trushkova E.A., Fesko O.V. (2012) Software package for optimization of regional development strategy in respect of innovations. Program Systems: Theory and Applications, vol. 3, no 5 (14), pp. 7-22 (in Russian).

3. Makarov V.L., Wu J., Wu Z., Khabriev B.R., Bakhtizin A.R. (2019) World trade wars: new impact estimation tools. Herald of the Russian Academy of Sciences, vol. 89, no 7, pp. 745-754 (in Russian). DOI: $10.31857 /$ S0869-5873897745-754.

4. Makarov V.L., Bakhtizin A.R., Beklaryan G.L., Akopov A.S., Rovenskaya E.A., Strelkovskiy N.V. (2019) Aggregated agent-based simulation model of migration flows of the European Union countries. Economics and Mathematical Methods, vol. 55, no 1, pp. 3-15 (in Russian). DOI: 10.31857/S042473880004044-7.

5. Makarov V., Ayvazyan S., Afanasyev M., Bakhtizin A., Nanavyan A. (2016) Modeling the development of regional economy and an innovation space efficiency. Foresight and STI Governance, vol. 10, no 3 , pp. 76-90 (in Russian). DOI: 10.17323/1995-459X.2016.3.76.90.

6. Beklaryan G. (2019) Aggregated simulation model of a region: Problems of Krasnoyarsk Region. Economics and Mathematical Methods, vol. 55, no 3, pp. 47-61 (in Russian). DOI: $10.31857 / \mathrm{S} 042473880005769-4$.

7. Makarov V.L., Bakhtizin A.R., Beklaryan G.L. (2019) Developing digital twins for production enterprises. Business Informatics, vol. 13, no 4, pp. 7-16. DOI: 10.17323/1998-0663.2019.4.7.16

8. Makarov V.L., Bakhtizin A.R., Sushko E.D. (2018) Computer modeling of socio-economic processes. Artificial Societies (electronic journal), vol. 1. Available at: https://cemi.jes.su/s111111110000104-7-1/ (accessed 06 November 2019) (in Russian). DOI: 10.33276/S0000104-7-1.

9. Andreichicov A.V., Andreichicova O.N. (2015) System analysis and synthesis of strategic decisions in innovation. Moscow: Lenand (in Russian).

10. Khaliullina D.N. (2014) Brief review of present-day methods for monitoring of complex social and economic region systems. Trudy Kol'skogo Nauchnogo Centra RAN, vol. 5, no 14, pp. 185-195 (in Russian).

11. Zhukov R.A. (2015) Implementation economics and mathematical software packages into the work of state administration. Fundamental Research, vol. 9, no 3, pp. 555-559 (in Russian).

12. Zhukov R.A., Vasina M.V., Soboleva D.V. (2019) Implementation of algorithm of calculation of the harmony coefficient on the basis of an expert system. Vestnik Tul'skogo Filiala Finuniversiteta, vol. 1, pp. 218-223 (in Russian).

13. Drogobytsky I.N. (2011) System analysis in economics. Moscow: UNITY-DANA (in Russian).

14. Chernyak Yu.I. (1975) System analysis in economic management. Moscow: Economics (in Russian).

15. Bertalanffy L. (1962) General system theory - A critical review. General Systems, vol. VII, pp. 1-20.

16. Kleiner G.B, Rybachuk M.A. (2017) System balance of the economy. Moscow: Scientific Library (in Russian).

17. Saaty T.L. (1993) Decision-making: The Analytic Hierarchy Process. Moscow: Radio and Communications (in Russian). 
18. Mesarovich M., Mako D., Takahara I. (1973) Theory of hierarchical multilevel systems. Moscow: Mir (in Russian).

19. Voronin A.A., Mishin S.P. (2003) Optimal hierarchical structures. Moscow: ICS RAS (in Russian).

20. Kolesnikov N.G., Tolstoguzov O.V. (2016) Structural changes in the economy of the Russian Northwest: Spatial dimension. Baltijskij Region, vol. 8, no 2, pp. 30-47 (in Russian). DOI: $10.5922 / 2074-9848-2016-2-2$.

21. Kleiner G.B. (2016) Economy. Modeling. Mathematics. Selected Works. Moscow: CEMI RAS (in Russian).

22. Zhukov R.A. (2018) Model of socio-ecological and economic system: The Central Federal District regions of the Russian Federation. Statistika: Statistics and Economy Journal, vol. 98, no 3, pp. 237-261.

23. Zhukov R.A. (2019) Socio-ecological-economic systems: Theory and practice. Moscow: INFRA-M (in Russian). DOI: 10.12737/monography_5b7516626665a8.43347695.

24. Zhukov R., Kuznetsov G., Gorodnichev S., Manokhin E., Nazyrova E., Melay E. (2019) Comparative analysis of results of assessing the Central Federal District's regions' economic development by using linear and non-linear models. Statistika: Statistics and Economy Journal, vol. 99, no 3, pp. 272-286.

25. Mishra S., Nathan H.S.K. (2013) Measuring Human Development Index: The old, the new and the elegant. Indira Gandhi Institute of Development Research. Available at: http://www.igidr.ac.in/pdf/ publication/WP-2013-020.pdf (accessed 01 June 2019).

26. Safiullin M.R., Elshin L.A., Prygunova M.I., Galyavov A.A. (2016) A probabilistic model for the forecasting of regional development of productive forces. Kazan Economic Vestnik, no 4 (24), pp. 94-99 (in Russian).

27. Ayvazyan S.A. (2012) Analysis of the quality and lifestyle of the population. Moscow: Nauka (in Russian).

28. Palash S.V. (2017) Structural balance of the economy: government programs for industrial development in the Russian Federation. St. Petersburg State Polytechnic University Journal of Engineering Science and Technology, vol. 10, no 1, pp. 53-72 (in Russian). DOI: 10.18721/JE.10105.

29. Zhu X., Zhao Z., Yan R. (2019) Coupling coordinated development of population, marine economy, and environment system: A case in Hainan province, China. Journal of Coastal Research, no 98, pp. 18-21. DOI: 10.2112/SI98-005.1.

30. Malakhov D.I, Pilnik N.P. (2013) Methods of estimating of the efficiency in stochastic frontier models. Higher School of Economics Economic Journal, no 4, pp. 692-718 (in Russian).

31. Zhukov R.A. (2019) Some optimization problems of the management of socio-ecological-economic systems. Chebyshevskii Sbornik, vol. 20, no 1, pp. 370-388 (in Russian). DOI: 10.22405/2226-83832019-20-1-370-388.

32. Moiseev N.N., Ivanilov Yu.P., Stolyarova E.M. (1978) Optimization methods. Moscow: Nauka (in Russian).

33. Podinovsky V.V., Nogin V.D. (1982) Pareto-optimal solutions to multicriteria problems. Moscow: FIZMATLIT (in Russian).

34. Zakharova E.M., Minashina I.K. (2014) Review of multidimensional optimization techniques. Information Processes, vol. 14, no 3, pp. 256-274 (in Russian).

35. Zhukov R.A. (2020) Software package for evaluating the functioning of complex systems and decision making "EFRA". Certificate of Registration of the Computer Program RU 2020614151, 26.03.2020.

\section{About the author}

\section{Roman A. Zhukov}

Cand. Sci. (Phys.-Math.), Associate Professor;

Researcher, Associate Professor, Department of Mathematics and Informatics,

Financial University under the Government of the Russian Federation,

Tula Branch, 1a, Oruzheynaya Street, Tula 300012, Russia;

E-mail: pluszh@mail.ru

ORCID: 0000-0002-2280-307X 